\title{
Tumor-derived Vascular Endothelial Growth Factor and Angiopoietin-2 in Non-small Cell Lung Cancer
}

\author{
Eman Obaia * Tarek Mohsen **, Amany Abou Zeid*** \\ Departments of Biochemistry*, Cardiothoracic Surgery**and \\ Chest Medicine*** Faculty of Medicine, Cairo University
}

\begin{abstract}
Lung cancer is a common disease with a dismal prognosis. Accurate staging is crucial for defining operability, selecting treatment regimens, and predicting survival. Methods of mediastinal lymph node staging include imaging and surgical sampling by different tools with many disadvantages. Angiogenesis is essential process in tumor growth, maintenance and metastasis. The tumor with high vessels density is related to metastasis and poor clinical outcome. Angiogenesis is regulated by balance between stimulatory and inhibitory regulators of endothelial cell activation. Vascular endothelial growth factor (VEGF) and Angiopoietin-2 (Ang-2) are two of the most potent angiogenic molecules. In this study we were evaluated the clinical effectiveness of serum level of Ang-2 and VEGF to aid management decision relating to diagnosis and staging of non-small cell lung cancer (NSCLC). The present work was conducted on 60 subjects. They were divided into 3 groups. Group 1 (15 healthy volunteers), Group 2 (15 patients with pulmonary diseases other than cancer) and Group 3 (30 patients with NSCLC).The latter were divided into two subgroups: Group 3a:15 patients with operable (NSCLC), and Group 3b:15 patients with non-operable NSCLC). Serum levels of Ang-2 and VEGF in different groups were measured using ELISA technique. The serum Ang-2 and VEGF were significantly higher in patients with NSCLC than patients with non-neoplastic lesions compared to healthy controls $(p<0.001)$.There was a significant positive correlation between both levels in patients with NSCLC. With stage progression in NSCLC, the non-operable group (3b) had significantly higher levels than operable group (3a). Patients with distant metastasis had higher levels than those without $(p<0.001)$. But, no notable significant differences were found in either serum levels of VEGF or Ang-2 concerning the cell type. Among 30 NSCLC patients, stages of 7 patients (23.3\%) were misdiagnosed because of they had normal sized lymph node on CT image. Five of them were Squamous carcinoma and the other two were adenocarcinoma on histopathological examination that need mediastioscopy. But, all NSCLC patients had high level of both markers according to their nodal staging. The operable group (3a) showed significant decrease in both levels after surgical resection $(P<0.001)$. Conclusion: The present findings suggest that assessment of circulating levels of VEGF and Ang-2 may be simple noninvasive future tools for diagnosis, staging, treatment planning and monitoring of treatment in patients with NSCLC.
\end{abstract}

Keyword: Angiopoietins, Vascular endothelial growth factor. (VEGF), non-small cell lung cancer (NSCLC) 


\section{INTRODUCTION}

Non Small Cell Lung Cancer (NSCLC) is a common leading cause of cancer death worldwide regardless of advances in therapeutic agents. NSCLC accounts for approximately $75-80 \%$ of all lung cancer cases. The staging of lung cancer defines the extent of the disease. The prognosis varies according to stage, with 5-year survival rates for stage I of $42 \%$, stage II of $23 \%$, stage IIIA of $11 \%$, stage IIIB of $5 \%$, and stage IV of $1 \%$. Accurate staging is crucial for defining operability, selecting treatment regimens, and predicting survival $^{(1)}$.

Solid tumors can not grow 1-3 $\mathrm{mm}$ without being subjected to hypoxia, they require a functional vasculature to grow and metastasis. To achieve this, tumor cells produce angiogenic factors that induce the formation of new blood vessels from the pre-existing vasculature (Angiogenesis) $^{(2)}$.

Angiogenesis is regulated by complex signaling pathways acting on endothelial cells that stimulate cell proliferation, migration and subsequent tube formation ${ }^{(3)}$. The level of angiogenic activity within a tissue is determined by the balance between stimulatory and inhibitory regulators of endothelial cell activation.

The proangiogenic factors include many growth factors, proteases and cytokines $^{(4)}$. Of these, vascular endothelial growth factor (VEGF) is a specific endothelial mitogen and a potent inducer of vessel permeability and angiogenesis. VEGF is a homodimeric 34 - to $42-\mathrm{kDa}$ heparin binding glycoprotein. Its activity is mediated by two high affinity tyrosine kinase receptors (flt-1: fms-like tyrosine kinase and flk-1: fetal liver kinase-1). Flk-1 is a major regulator of angiogenesis both in vivo and in vitro. Four isoforms of VEGF (VEGF121，VEGF165, VEGF189, VEGF206) exist in human tissues ${ }^{(5)}$. VEGF is the most important angiogenic factor closely associated with induction and maintenance of the neovasculature. High expression of VEGF mRNA has been detected in a variety of tumors and might be considered an important prognostic marker of tumor angiogenesis ${ }^{(6)}$.

Angiopoietins are secreted glycoproteins that play a complex role in vascular development ${ }^{(7)}$. Angiopoietin-1 and -2 function as ligands for Tie2 which is a receptor tyrosine kinase specifically expressed on endothelial cells ${ }^{(8)}$. Angiopoietin-1 stabilizes blood vessels by promoting the interaction between endothelial cells and surrounding extracellular matrix. Angiopoietin-2 antagonize the stabilizing action of angiopoietin- 1 by binding to Tie2 competitively which destabilizes vessels. The destabilized vessels do not regress but undergo angiogenesis in the presence of angiogenic factors such as VEGF. Therefore, Angiopoietin-2 promotes tumor angiogenesis by priming the vasculature and potentiating the effects of VEGF at the front of active neovascularization ${ }^{(9)}$. The dynamic balance between Angiopoietin-1 and 2 along with VEGF controls tumor angiogenesis. In contrast to the relatively greater expression of angiopoietin-1 in normal tissue, the predominant expression of 
angiopoietin-2 in tumor tissue has been implicated as an angiogenic switch in tumorigenesis ${ }^{(\mathbf{1 0})}$.

Angiogenesis not only permit further growth of the primary tumor, but it also provides a pathway for migrating tumor cells to gain access to the systemic circulation and to establish distant metastasis ${ }^{(2)}$.

Methods of mediastinal lymph node staging can be divided into imaging and sampling. Computed tomography (CT), magnetic resonance imaging (MRI), and positron emission tomography (PET) may be used to image mediastinal lymph nodes. Surgical pathological sampling of suspicious lesions can be performed by mediastinoscopy, mediastinotomy, thoracoscopy, transthoracic fineneedle aspiration, transbronchial fineneedle aspiration, and endoscopic ultrasonography with fine-needle aspiration $^{(11)}$.

Chest CT is the most commonly used noninvasive staging method of lymph node metastasis, but it is far from satisfying and less accurate than other tools because it provides excellent morphologic information on the extent of disease but has limited ability to differentiate between benign and malignant lesions ${ }^{(\mathbf{1 2})}$. MRI is more accurate than $\mathrm{CT}$ due to its ability to detect invasion of major mediastinal structures, better soft tissue contrast, multiplanar imaging capability, but it is slow, expensive, poorly tolerated by claustrophobic patients and is contra-indicated in patients with indwelling electromagnetic devices and some prosthetic heart valves ${ }^{(13)}$. 18fluordeoxyglucose PET scanning is a new imaging modality, its advantage over other modalities lies in its sensitivity (about 67-100\%) and its ability to image the entire body in one examination. The main disadvantages of PET are the lack of availability and relatively the high cost of each examination. PET is not suitable for the detection of brain metastasis due to high glucose uptake in normal brain tissue ${ }^{(14)}$. Although, mediastinoscopy is regarded as the gold standared methods for mediastinal staging, it is an invasive technique ${ }^{(\mathbf{1 5})}$. Being faced by these difficulties and inconveniences in staging of NSCLC, doctors urgently need easier, alternative and non-invasive methods for staging of NSCLC.

In this study, we were measured and compared the serum levels of angiopoietin-2 and VEGF in NSCLC patients with different stages versus patients with pulmonary diseases other than cancer and healthy control aiming to evaluate the clinical effectiveness of serum level of angiopoietin-2 and VEGF to aid management decision relating to diagnosis and staging of non-small cell lung cancer (NSCLC).

\section{SUBJECTS \& METHODS}

The present work was conducted on 45 patients and 15 normal healthy volunteers. They were among the patients attending Chest Department in Kasr El Aini hospital, Cairo University. Thery were 34 male and 26 female with mean age of 53 years (range, 41-71). They were divided into 3 groups as follow:

*Group 1 (n=15): normal healthy volunteers. 
*Group 2 (n=15): patients with non malignant pulmonary disease. Four patients had interstitial lung disease (ILD), three patients had lung abscess, three patients had pulmonary T.B, two patients had bronchiectasis, another 2 were diagnosed as pulmonary embolism and finally one with pulmonary sequestration.

*Group $3 \quad(\mathbf{n}=\mathbf{3 0})$ : patients with NSCLC . They were divided into two subgroups: group $3 a(n=15)$ : operable NSCLC (stage 1, 11 and 111A) and group $3 \mathrm{~b} \quad(\mathrm{n}=15)$ : non-operable NSCLC (stage 111B and 1V).

All participants had informed consent. They were subjected to history taking, clinical examination and routine laboratory investigations. Patients in groups 2 and 3 were subjected to chest X-ray, CT scan and fibro-optic bronchoscopy to confirm the diagnosis. Additional investigations were done to aid in staging NSCLC in group 3, these include:

1- Mediastinal staging: The mediastinum was scanned at 5-8 $\mathrm{mm}$ interval and the nodal stage was determined by CT scan .Mediastinal lymph nodes $\geq 1 \mathrm{~cm}$ were considered to be metastatic. Other tools were used for pathological sampling.

The tumor stage was determined according to TNM subsets ${ }^{(\mathbf{1 6})}$ ( $\mathrm{T}=$ primary tumor, $\mathrm{N}=$ regional lymph nodes, $\mathrm{M}=$ distant metastasis) in the International System for Staging into:

*Stage IA: T1 N0 M0, stage IB: T2 N0 M0,

*Stage IIA: T1 N1 M0, stage IIB: T2 N1 M0 and T3 N0 M0,

*Stage IIIA: T3 N1 M0, T1 N2 M0, T2 N2 M0, T3 N2 M0, stage IIIB: T4 anyN M0, anyT N3 M0 .

*Stage IV: anyT anyN M1.
Classification to operable or inoperable NSCLC (i.e. staging) was according to Mountain's classification (16), in which stages IA, IB, IIA, IIB and IIIA are operable, while stages IIIB and IV are inoperable.

2-Distant metastasis was determined by brain MRI, abdominal ultrasonography and bone scan.

Patient with NSCLC had no active infection or inflammatory disease or had received blood transfusion, radiotherapy or chemotherapy before the study.

Blood samples were obtained from all participant after an over night fasting. Then, the samples were centrifuged at $3000 \mathrm{rpm}$ for $10 \mathrm{~min}$ and sera were separated and stored at $80^{\circ} \mathrm{C}$ until the assay. Serum angiopoietin-2 and VEGF levels were determined by enzyme linked immunosorbent assay (ELIZA) using kits provided by Quantikine, R\&D system, Inc. Minneapolis, USA.

Statistical Analysis:

The results were analyzed using SPSS computer software package, version 10.0 (Chicago-IL, USA) ${ }^{(17)}$. Data were presented as mean \pm S.D. Differences among the four groups were compared by one-way ANOVA test and student $\mathrm{T}$ test. To study the relationship between the measured parameters in separate groups, Pearson's correlation was calculated. The results were considered statistically significant at $\mathrm{P}<0.05$.

\section{RESULTS}

The characteristics of patients involved in this work are shown in table 1 . 
Table 1. Demographic data of different subjects

\begin{tabular}{l|llll}
\hline & $\begin{array}{l}\text { Group 1 } \\
\text { Control }\end{array}$ & $\begin{array}{l}\text { Group 2 } \\
\text { Non-malignant } \\
\text { cause }\end{array}$ & $\begin{array}{l}\text { Group 3a } \\
\text { Operable } \\
\text { NSCLC }\end{array}$ & $\begin{array}{l}\text { Group 3b } \\
\text { Non-operable } \\
\text { NSCLC }\end{array}$ \\
\hline Subjects number & 15 & 15 & 15 & 15 \\
Age (year) & $51.9 \pm 6.6$ & $48.1 \pm 10$ & $51.4 \pm 9$ & $59.2 \pm 7.4$ \\
Sex (male/female) & $9 / 6$ & $6 / 9$ & $10 / 5$ & $11 / 4$ \\
Smokers & $2(13.3 \%)$ & $6(40 \%)$ & $11(73.3 \%)$ & $15(100 \%)$ \\
\hline
\end{tabular}

Table 2. Pathological cell type and staging of group 3:

\begin{tabular}{l|ll}
\hline & $\begin{array}{l}\text { Group 3a } \\
\text { (operable NSCLC) }\end{array}$ & $\begin{array}{l}\text { Group 3b } \\
\text { (non-operable NSCLC) }\end{array}$ \\
\hline $\begin{array}{l}\text { Pathology } \\
\text { a) Squamous cell carcinoma. }\end{array}$ & 9 patients $(60 \%)$ & 11 patients $(73.3 \%)$ \\
$\begin{aligned} \text { b) Adenocarcinoma. } \\
\text { Stages }\end{aligned}$ & 6 patients $(40 \%)$ & 4 patients $(26.6 \%)$ \\
& II A 4 $(26.6 \%)$ & IIIB 5 $(33.3 \%)$ \\
& II B 6 $(40 \%)$ & IV $10(66.6 \%)$. \\
\hline
\end{tabular}

In group 3a (operable NSCLC), there were 15 patients who underwent surgical resection. Pathological cell type and staging are shown in table 3.

In group $3 \mathrm{~b}$ (non-operable lung cancer), there were 15 patients who during staging process were deemed not operable due to advanced stage. Pathological cell type and staging are shown in table 2 .

Table 3. Serum levels of VEGF and angiopoietn-2 in different groups

\begin{tabular}{l|lllll}
\hline & Group 1 & Group 2 & Group 3a & Group3b & P value \\
\hline VEGF pg/ml & $28.24+3.5$ & $32.06+3.27$ & $246.26+44.2$ & $380.46=54.06$ & $<0.001$ \\
Ang-2 pg/ml & $1199.8+314.1$ & $1200.2+312.4$ & $1624.9+294.68$ & $2881.39=759.7$ & $<0.001$ \\
& & & & & \\
\hline \multicolumn{5}{c}{ Values are expressed as mean + SD } & \multicolumn{3}{c}{$P<0.05:$ significant } \\
VEGF: vascular endothelial growth factor & \multicolumn{2}{c}{ Ang-2: angiopoietn-2 }
\end{tabular}

The serum VEGF and angiopoietn-2 levels were significantly higher in the patients with NSCLC (operable and inoperable) versus patients with nonneoplastic lesions and healthy control $(<0.001)$ (table 3). 
Table 4: Comparison of serum levels of VEGF and angiopoietn-2 according to cell type among patients with NSCLC

\begin{tabular}{|c|c|c|c|c|}
\hline Cell type & Group3 & $\begin{array}{c}\text { Cases No. } \\
n=30\end{array}$ & $\begin{array}{l}V E G F \\
\mathrm{pg} / \mathrm{ml}\end{array}$ & $\begin{array}{c}\text { Ang-2 } \\
\mathrm{pg} / \mathrm{ml}\end{array}$ \\
\hline Squamous cell & G3a & $9(60 \%)$ & $234.6 \pm 68.9(a)$ & $1674.17 \pm 158.6(\mathrm{c})$ \\
\hline Adenocarcinoma & $\mathrm{N}=15$ & $6(40 \%)$ & $248.6 \pm 78.7(a)$ & $1524.17 \pm 195.3(\mathrm{c})$ \\
\hline Squamous cell & $\mathrm{G} 3 \mathrm{~b}$ & $11(73.3 \%)$ & $365.37 \pm 70.9(b)$ & $2748.01 \pm 410.6(\mathrm{~d})$ \\
\hline Adenocarcinoma & $\mathrm{N}=15$ & $4(26.6 \%)$ & $372.37 \pm 80 \quad$ (b) & $2626.01 \pm 269.4(\mathrm{~d})$ \\
\hline
\end{tabular}

Values are expressed as mean $+S D$.

VEGF: vascular endothelial growth factor.

Similar letters $(a, b, c)$ indicate non significant difference between groups.

Difference in litter indicates significant differences.

No notable difference were found in either Serum of VEGF and angiopoietn-2 levels according to cell type among patients with NSCLC (table 4).

Table 5: Comparison of serum levels of VEGF and angiopoietn-2 according to tumor progression among patients with NSCLC

\begin{tabular}{|l|l|l|l|l|}
\hline Stage & Cases No. & $\begin{array}{l}\text { VEGF } \\
(\mathrm{pg} / \mathrm{ml})\end{array}$ & $\begin{array}{l}\text { Angiopoietin-2 } \\
(\mathrm{pg} / \mathrm{ml})\end{array}$ & $\mathrm{P}$ value \\
\hline Operable group 3a & $(\mathrm{n}=15)$ & & & $\mathrm{P}<0.001$ \\
II A $(26.6 \%)$ & $4(26.6 \%)$ & $248 \pm 68.7(\mathrm{a})$ & $1524.1 \pm 938.1$ (a) & \\
II B (40\%) & $6(40 \%)$ & $253 \pm 78.3(\mathrm{a})$ & $1615.2 \pm 759.3$ (a) & \\
III A (33.3\%). & $5(33.3 \%)$. & $279 \pm 86.1(\mathrm{a})$ & $1771.5 \pm 937.0$ (a) & \\
\hline Inoperable group 3b & $(\mathrm{n}=15)$ & & & $\mathrm{P}<0.001$ \\
III B (33.3\%) & $5(33.3 \%)$ & $401.5 \pm 70.3(\mathrm{~b})$ & $3179.9 \pm 893.5(\mathrm{~b})$ & \\
IV (66.6\%). & $10(66.6 \%)$. & $539 \pm 88.4(\mathrm{c})$ & $422.7 \pm 968.9(\mathrm{c})$ & \\
\hline
\end{tabular}

Values are expressed as mean $+S D$.

$V E G F$ :vascular endothelial growth factor.

Similar letters $(a, b, c)$ indicate non significant difference between groups.

Difference in litter indicates significant differences.

Serum level of VEGF and Ang-2 were compared according to stage progression. The non-operable group
(G3b) had significantly greater levels than operable group (G3a). 
Table 6. Comparison between CT nodal staging, serum levels of VEGF \& angiopoietn-2 and pathology in patients with NSCLC

\begin{tabular}{l|lll}
\hline Lymph node size & CT & Serum markers & Pathology \\
\hline Normal size & $7(23.3 \%)$ & VEGF: 253 \pm 78.3 & 5 Squamous carcinoma \\
& & Ang-2: 1615.2 \pm 759.3 & 2 adenocarcinoma \\
Enlarged size $(\geq 1 \mathrm{~cm})$ & $23(76.6 \%)$ & VEGF: 401.5 \pm 70.3 & 15 Squamous carcinoma \\
& & Ang-2: 3179.9 \pm 893.5 & 8 adenocarcinoma \\
Total No. & $30(100 \%)$ & $30(100 \%)$ & $30(100 \%)$ \\
\hline
\end{tabular}

Values are expressed as \% and mean $+S D$.

VEGF:vascular endothelial growth factor

Normal sized lymph nodes were demonstrated in 7 of 30 patients with NSCLC on CT image .But these 7 patients had high levels of VEGF and Ang-2 and received a node positive pathologic diagnosis ( 5 of them were squamous carcinoma and the other 2 were adenocarcinoma). Enlarged sized lymph nodes were demonstrated in 23 of 30 patients with NSCLC on CT image .All of them had high levels of VEGF and Ang-2 and received a node positive pathologic diagnosis (15 of them were squamous carcinoma and the other 8 were adenocarcinoma).

Table 7. Serum levels of VEGF and angiopoietn-2 in operable group (3a) before and after resection

\begin{tabular}{l|lll}
\hline & Before resection & After resection & P value \\
\hline VEGF ( pg/ml) & $246 \pm 44.2$ & $137.46 \pm 29.8$ & $<0.001$ \\
Angiopoietin-2 (pg/ml) & $1624.9 \pm 294.68$ & $874.4 \pm 174.2$ & $<0.001$ \\
\hline Values are expressed as mean \pm SD. & $P<0.05:$ significant \\
VEGF: vascular endothelial growth factor & & \\
& & & \\
Serum levels of VEGF and & were decreased significantly after \\
angiopoietn-2 in operable group (3a) & resection of primary tumor (table7).
\end{tabular}




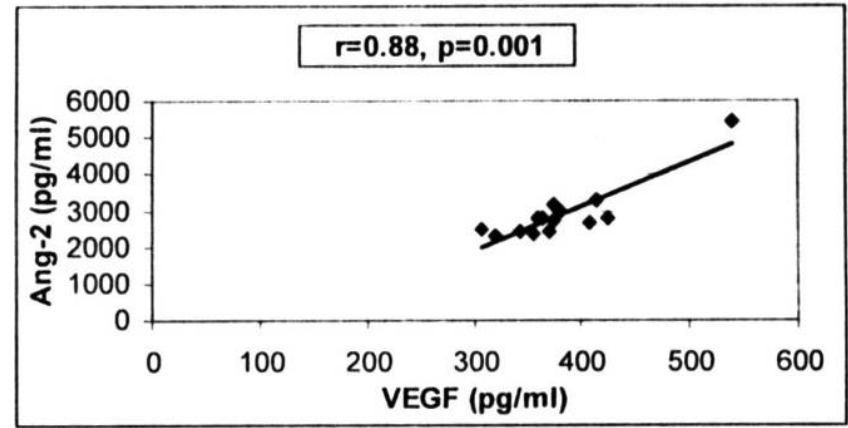

Fig 1: Correlation between serum VEGF and Ang-2 in inoperable group

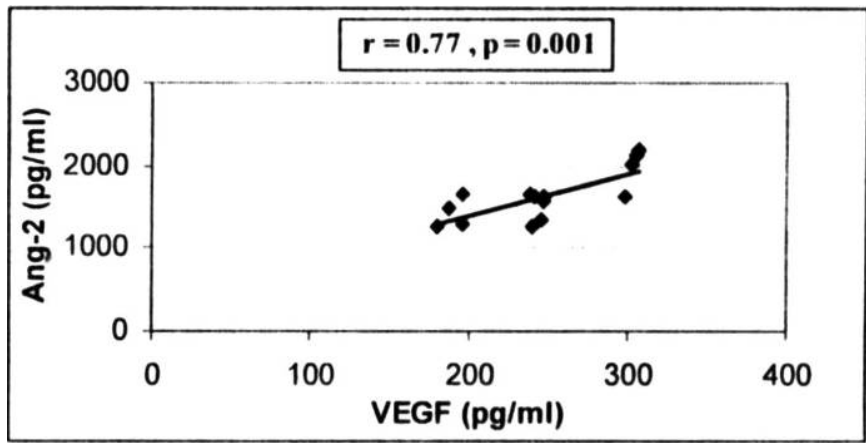

Fig 2: Correlation between VEGF and Ang-2 in operable group before resection

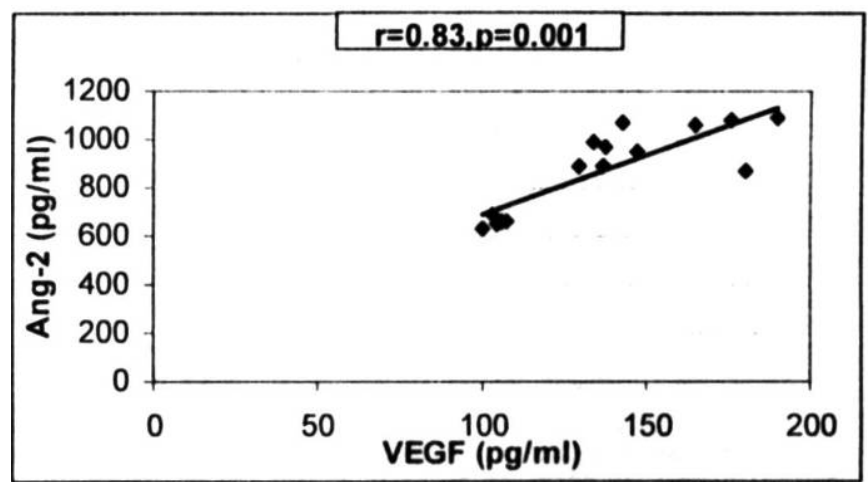

Fig 3: Correlation between VEGF and Ang-2 in operable group after resection 


\section{DISCUSSION}

Angiogenesis is an essential process in development and progression of malignant tumors. The tumor with high blood vessels density is related to the extension of metastasis and poor clinical outcome $^{(\mathbf{1 8 )}}$. VEGF and Ang-2 are two of the most potent factors involved in $\operatorname{angiogenesis}^{(\mathbf{1 9})}$. Angiopoietin-2 play a critical role in the angiogenesis in concert with $\operatorname{VEGF}^{(\mathbf{2 0})}$.

In the present study, higher VEGF serum level was demonstrated in patients with NSCLC than patients with non-neoplastic lesions compared to healthy controls. These results are in agreement with Ohta et al. ${ }^{(21)}$ who demonstrated high level of VEGF in bronchoalveolar lavage in patients with NSCLC, Thickett et al. ${ }^{\text {(22) }}$ demonstrated high level of VEGF in serum and malignant effusions of patients with lung cancer and Matsuyama et al. ${ }^{\text {(23) }}$ showed high level of serum VEGF in patients with NCSLC and significant increase with disease progression.

Angiopoietin-2 operates closely with VEGF in tumor angiogenesis and its overexpression in lung cancer tissue is related to a poor prognosis ${ }^{(24)}$. The preset study showed also higher serum level of angiopoietin-2 in patients with NSCLC than patients with non-neoplastic lesions compared to healthy controls .However, few studies have ever examined its clinical implications in serum .There are many studies examined its expression in tumor cell .The current results are in agreement with Joo Hun Park et al. ${ }^{(25)}$ who demonstrated an increase in serum Ang-2 in NSCLC. An increased expression of Ang-2 in tumor cells was reported by a lot of study as Hatanaka et al. ${ }^{(26)}$ and Fumihiro et al. $^{(27)}$.

The present data showed that the serum levels of Ang-2 and VEGF in malignancy (lung cancer) were significantly high as compared to other lung diseases.So, inhibition of specific processes essential for tumor vascular development is actually one of the key strategies for treatment of lung cancer ${ }^{(28)}$.

Angiopoietin-2 and VEGF are reported as critical regulators of this angiogenic process and are associated with the surviving tumor and promoting further growth ${ }^{(29)}$. These interactions between VEGF and Ang2 may explain the significant positive correlation between the two factors that we observed in patients with NSCLC in the present study. These results were in accordance with Fumihiro et al. ${ }^{\mathbf{( 2 8 )}}$ who demonstrated that low CD105-IMVD (a measurement of angiogenesis) for Ang-2 positive tumor in the absence of high expression of VEGF, Whereas it was elevated to the highest value in the presence of high VEGF. Also, Yancopoulos et al. ${ }^{(\mathbf{3 0})}$ and Yoshiji et al. ${ }^{(31)}$ reported that angiogenesis is promoted by Ang-2 in concert with VEGF.

Lung cancer is a common disease with a dismal prognosis. Even after a complete resection, over two thirds will die from a relapse within 5 years $^{(\mathbf{1})}$. The first important decision concerns whether or not to operate, in order to avoid surgical risks without benefit. The second question concerns 
whether or not to provide neoadjuvant therapy. Both questions must be answered relying on preoperative staging. Although the CT scan is very helpful as an initial screen, it is relatively insensitive in detecting invasion, as compared with surgical staging $^{(32)}$. Several studies have demonstrated that $\mathrm{CT}$ scans have a sensitivity of $79 \%$ for identifying positive mediastinal adenopathy. The specificity of CT for detecting metastatic lung cancer is even lower $(65 \%)$ when compared to surgical staging. Computed tomography is approximately $85 \%$ accurate in predicting malignant lymph nodes when these nodes are greater than 1.5 $\mathrm{cm}$ in size ${ }^{(33)}$.

In the preset study, the staging of $7 / 30(23.3 \%)$ patients with NSCLC were misdiagnosed because they had normal sized lymph nodes on CT image. Five of them were squamous carcinoma and the other two were adenocarcinoma on pathological diagnosis that need mediastioscopy. But, all NSCLC patients had high level of both markers according to their nodal staging.

These data were in accordance with Takeshi et al. ${ }^{(34)}$ who suggested that the high frequency of the normal sized N2 mediastinal lymph nodes is directly affect the sensitivity of CT. These finding indicate that differentiation between malignant lymph nodes and benign nodes depending on size is not reliable. Invasive staging such as mediastinoscopy was used when mediastinal lymph nodes was found to be $>1 \mathrm{~cm}$ in its longest diameter in the mediastinal window of the chest CT. Although, this is still controversial, as a number of thoracic surgeons believe that mediastinoscopy should be performed in all cases of suspected lung cancer because its sensitivity and specificity rates of approximately 85 $\%$ and $100 \%$, respectively that exceed those of chest $\mathrm{CT}^{(35)}$.

In present study, with tumor progression, the serum levels of VEGF and Ang-2 were significantly greater in the non-operable group with advanced stages (111B-1V) who exhibited mediastinal lymph node metastasis or distant metastasis than in the operable group with early stages (11A, 11B and 111A). But no notable significant difference were found in either Serum of VEGF or angiopoietn2 levels according to cell type whether adenocarcinoma or squamous cell carcinoma.

These data could be considered similar to Kaya et al. ${ }^{(36)}$, Matsuyama et al. ${ }^{(37)}$ and Laack et al. ${ }^{(38)}$ who reported a significant relationship between serum VEGF levels in lung cancer and stage progression. In contrast, Joo Hun Park et al. ${ }^{(25)}$ reported that serum VEGF levels did not increase with stage progression and only had a trend toward elevation in distant metastasis. On the other hand, the serum Ang-2 levels increased with stage progression and patients with distant metastasis had higher levels than those without metastasis and explained his results by the small number of patients in advanced stages that included in the study.

In this study, the serum VEGF and Ang-2 levels were valuable than CT scan. The only CT imaging criteria for tumor involvement are morphologic; that is, the criteria rely 
on the size and shape of the lymph nodes. But, the metastasis of normalsized regional lymph nodes may be revealed as malignancy by histological examination. However, nodal enlargement may be due to reactive hyperplasia or other nonmalignant conditions ${ }^{(39)}$. We can say that the high serum VEGF and Ang-2 represent lymph node involvement in malignancy more precisely than nodal enlargement. So, both markers evaluation and $\mathrm{CT}$ examination are complementary to each other for accurate lymph node staging in NSCLC.

Tamura et al. ${ }^{(40)}$ reported that combined diagnosis by serum markers and CT is relatively accurate, but there are false-positive as well as false-negative cases. It may be dangerous to start induction of chemotherapy solely relying on CT or VEGF levels. Invasive staging such as mediastinoscopy cannot be omitted, but we believe that the presented combination diagnosis provides helpful information to select patients who need or do not need mediastinoscopy.

The present study also showed that serum Ang-2 and VEGF levels in operable group were decreased significantly after resection of the primary tumor. These in accordance with Joo Hun Park et al. ${ }^{(25)}$ who demonstrated that in patient with NSCLC who underwent complete surgical resection, the serum Ang-2 levels were higher in patients with a post-operative recurrence than those without and serum VEGF level did not differ meaningfully in terms of tumor recurrence. By contrast, Yilmaz et al. ${ }^{(41)}$ who reported that strong
VEGF immunostaining in tumor tissues was found to be an important prognostic factor for time to relapse and survival in patients with early stage disease. Also, Reinmuth et al. ${ }^{(42)}$ reported that alveolar vessel architecture and angiopoietin expression appear to be common phenomenons in early stage NSCLC and may serve as prognostic factors. After resection of the tumor, decreased levels of circulating Ang-2 and VEGF would reflect a balance between the loss of the tumor stimulus and the addition of regeneration stimulus. Also, surgical trauma with subsequent release of various proteolytic enzymes involved in healing of the wound may degrade them. This results demonstrates the potential to predict recurrence after resection in patients with early-stage nonsmall-cell lung cancer using serum level of Ang-2 and VEGF.

In future, a much larger scale analysis would be required to assess the feasibility of using circulating VEGF and Ang-2 as tumor markers of recurrence and treatment response which need long period of follow up. Further studies are needed to evaluate different isoforms of VEGF, the expression of Tie2 along with the underlying signaling of angiopoietin ligands that might lead to a novel treatment strategies to inhibit tumor angiogenesis.

In conclusion, the serum levels of VEGF and Ang-2 were found to be significantly high in patients with NSCLC especially those with advanced stages (111B and 1V) more than patients with non-neoplastic lesions compared to healthy control. Thus, they might be reliable markers 
for diagnosis of NSCLC. The significant elevation of serum levels of VEGF and Ang-2 with stage progression compared to other tools might be considered as indicator of tumor invasion and metastasis. It could be used as noninvasive, easily performed, and inexpensive markers for staging (the extent of local and distant metastasis) and accurate management decision (operability). The significant decrease of serum levels of VEGF and Ang-2 after surgical resection might be used for treatment follow up.

\section{REFERENCES}

1- Kim ES, (2007): The importance of accurate lymph node staging in early and locally advanced nonsmall cell lung cancer: an update on available techniques. J Thorac. Oncol. Jun;2 Suppl 2:S59-67.

2- Folkman J. (1990): What is the evidence that tumors are angiogenesis dependent? J. Nati .Cancer Inst; $82: 4-6$.

3- Folkman, J. and Shing, Y. (1999): Angiogenesis. J. Biol. Chem., 267: 10931-10934.

4- Folkman, J. (2000): Role of angiogenesis in tumor growth and metastasis. Semin.Oncol. 29(Suppl. 16): 15-18.

5- Yoshiji, H.; Kuriyama, S.; Hicklin, D.J.; et al. (1999): $\mathrm{KDR} / \mathrm{FIk}-1$ is a major regulator of vascular endothelial growth factor-induced tumor development and angiogenesis in murine hepatocellular carcinoma cells Hepatology 30: 1179-1186.

6- Ferrara N. (2002): Role of vascular endothelial growth factor in physiologic and pathologic angiogenesis: therapeutic implications. Semin., Oncol., 29(Suppl. 16): 10-14.

7- Hanahan, D.; and Folkman, J. (1996): Patterns and emerging mechanisms of the angiogemc switch during tumorigenesis. Cell, 86: 353-364.

8- Maisonpierre PC, Suuri C, Jones PF et al (1997): Angiopoietin-2, a natural antagonist for Tie2 that disrupts in vivo angiogenesis. Science, 87:1171-1180.

9- Peters KG. (1998): Vascular endothelial growth factor and the angiopoietins: working together to build a better blood vessel. Circ. Res: 83:342-343.

10- Holash J, Maisonpierre PC, Compton D, et al. (1999): Vessel coopration, regression, and growth in tumors mediated by angiopoietins and VEGF. Science; 284:1994-1998.

11- Mountain CF. (2000): The international system for staging lung cancer. Semin Surg .Oncol.; 18:106-115.

12- Hollings N, Shaw P. (2002): Diagnostic imaging of lung cancer. Eur. Respir. J., 19: 722742.

13- Hatabu H, Stock KW, Sher S. (1999): Magnetic resonance imaging of the thorax: Past, present, and future. Clin. Chest Med., 20: 775-803.

14- Kernstine KH, McLaughlin KA, Menda RY, et al. (2002): Can FDG-PET reduce the need for mediastinoscopy in potentially resectable non-small cell lung 
cancer? Ann .Thorac .Surg; 73:394-402.

15- Porte H, Roumilhac D, Eraldi L, et al. (1998): The role of mediastinoscopy in the diagnosis of mediastinal lymphadenopathy. Eur. J. Cardiothorac. Surg.; 13:196-199.

16- Mountain CF. (1997): Revisions in the international system for staging lung cancer. Chest, 111: 1710-1717.

17- Norusis M J (1997): SPSS 7.5 guide to data analysis, Simon and Schuster Company, Upper Saddle River. New Jersey.

18- Cox G, Jones J, Walker R, Steward W and Byme K (2000): Angiogenesis and NSCLC. Lung Cancer, 27:81-100.

19- Wong, M. P., Chan, S. Y., Fu, K. H., Leung, S. Y., Cheung, N, Yuen. S. T., and iung, L.P. (2000): The angiopoietins, Tie2 and vascular endothelial growth factor are differentially expressed in the transformation of normal lung to non-small cell lung carcinomas. Lung Cancer, 29: 1122 ,

20- Fontanini G, Vignati S, Boldrini L, et al. (1997): Vascular endothelial ZX growth factor is associated with neovascularization and influences progression of non-small cell lung carcinoma. Clin .Cancer Res ; 3:861-865.

21- Yasuhiko Ohta Y, Ohta N, Tamura M, Wu J, Tsunezuka $Y$, Oda $M$ and Watanabe $G$. (2002): Vascular endothelial growth factor expression in airways of patients with lung cancer: A possible diagnostic tool of responsive angiogenic status on the host side. Chest; 121:16241627.

22- Thickett DR, Armstrong L, Milla AB. (1999): Vascular endothelial growth factor (VEGF) in inflammatory and malignant pleural effusions. Thorax; 54:707-710.

23- Matsuyama W, Hashiguchi T, Mizoguchi A, Iwami F, Kawabata F, Arimura K, Osame M. (2000): Serum levels of vascular endothelial growth factor dependent on the stage progression of lung cancer. Chest; 118:948-951.

24- Yano S, Matsumori Y, Ikuta K, et al. (2006): Current status and perspective of angiogenesis and antivascular therapeutic strategy: non-small cell lung cancer. Int .J. Clin .Oncol: 11:73-81.

25- Joo Hun park, Kawang Joo park, Young Sun Kim, Seung Soo Sheen, keu Sung Lee, Hyoung No Lee,Yoon Jung Oh and Sung Chul Hwang (2007): Serum Angiopoietin-2 as a clinical marker for lung cancer.Chest,132:200-206.

26- Hatanaka, H., Abe, Y., Naruke, M. Tok'unaga, T., Oshita, Y., Kawakami, T., Osada, Nagata, J., Kamochi, J., Tsllchida, T., Kijima, H., Yamazaki. H., Inoue, H., Ueyama, Y., and Nakamura, $M \quad$ (2001): Significant correlation between interleukin 10 expression and vascularization through angiopoietin/Tie2 networks in nonsmall cell lung cancer. Clin. Cancer Res., 7: 1287-1292. 
27- Fumihiro, T.; Shinya, I; Kazuhiro, Y; Ryo, M; Yozo,K; Mio, L; Yosuke, $O$ and Hiromi,W (2002) :Expression of angiopoietins and its clinical significance in NSCLC.Cancer Research,62:7124-7129.

28- Pérol $M$ and Arpin D (2007): Angiogenesis and lung cancer. Bull. Cancer. 94: 220-231.

29- Holash J, Wiegand SJ, Yancopoulos GD. (1999): New model of tumor angiogenesis: dynamic balance between vessel regression and growth mediated by angiopoietins and VEGF. Oncogene .; 18:5356-5362.

30- Yancopoulos, G. D., Davis, S., Gale, N. W., Rudge, J. S., Wiegand. S. J., and Holash, (2000): Vascular-specific growth factors and blood vessel formation. Nature (Lond.), 407: 242-248.

31- Yoshiji H, Kuriyama S, Noguchi R, Yoshii J, Ikenaka Y, Yanase $K$, Namisaki T, Kitade $M$, Uemura $M$ and Masaki T (2005): Angiopoietin 2 displays a vascular endothelial growth factor dependent synergistic effect in hepatocellular carcinoma development in mice. Gut, December 1, 54 (12): 1768 - 1775 .

32- Whittesey D (1988): Prospective computed tomographic scanning in the staging of bronchogenic cancer. J. Thorac. Cardiovasc. Surg ; 95:876.

33- Herman SJ, Winton TJ, Weisbrod GL, et al (1994): Mediastinal invasion by bronchogenic carcinoma: CT signs. Radiology;190:841-846.
34- Takeshi A, Tsuneo M, Tatsuya K, Mitsutoshi K, Naofumi M, Kazuro $S$ and Kensuke $E$ (1996): Is possible to differentiate malignant mediastinal nodes from benign nodes by size?.Chest; 110:1004-1008.

35- Rendina EA, Venuta F, De Giacomo T, Ciriaco PP, Pescarmona EO, Francioni F, Pulsoni A, Malagnino F, Ricci C. (1994): Comparative merits of thoracoscopy, mediastinoscopy, and mediastinotomy for mediastinal biopsy. Ann. Thorac. Surg; 57:992-995.

36- Kaya A, Cilcdag A, Gulbay BE, ct al. (2004): The prognostic significance of vascular endothelial growth factor levels in sera of non-small cell lung cancer patients. Respir .Med; 98: 632-636.

37- Matsuyama W, Hashiguchi T, Mizoguchi A, et al. (2000): Scrum levels of vascular endothelial growth factor dependent on the stage progression of lung cancer. Chest; 118:948-951.

38- Laack E, Schefflcr A, Burkholder I, ct al. (2005): Pretreatment vascular endothelial growth factor (VEGF) and matrix metalloproteinase-9 (MMP-9) serum levels in patients with metastatic non-small cell lung cancer (NSCLC). Lung Cancer, 50:51-58.

39- Hans CS, Markus H, Florin A, et al. (1997): Non-small cell lung cancer: nodal staging with FDGPET versus CT with correlative lymph node mapping and 
sampling. Radiology; 202:441446.

40- Tamura M, Makoto O, Yoshio T, Isao $M$, Kazuyuki $\mathbf{K}$, Yasuhiko O, Go W(2004): Chest CT and serum vascular endothelial growth factor C-level to diagnose lymph node metastasis in patients with primary non small cell cancer. Chest; 126:342-346.

41- Yilmaz A, Ernam D, Unsal E, Demirag F, Atikcan S, Taştepe (2007): Vascular endothelial growth factor immunostaining correlates with postoperative relapse and survival in non-small cell lung cancer. Arch. Med. Res.; 38(7):764-8.

42- Reinmuth N, Piegelbrock E, Raedel $\mathbf{M}$, Fehrmann $\mathbf{N}$, Hintelmann $\mathbf{H}$, Wagner $\mathbf{R}$, Berdel WE, Thomas M, Freitag L, Mesters RM (2007): Prognostic significance of vessel architecture and vascular stability in non-small cell lung cancer. Lung Cancer. Jan; 55(1):53-60. 


\section{عامل النمو للغشاء المبطن للأوعية الدموية وانجيوبيوتن-r في الخلايا الغير صغيرة لسرطان الرئة النة

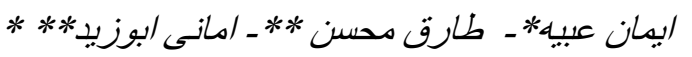

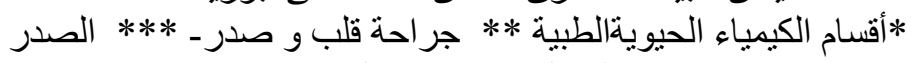 \\ كلية الطب- جامعة القاهرة
}

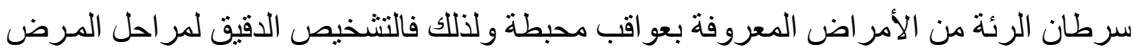

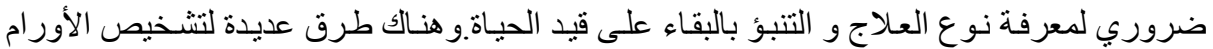

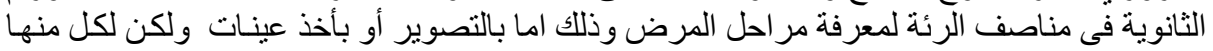

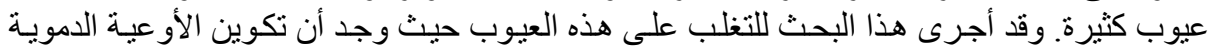

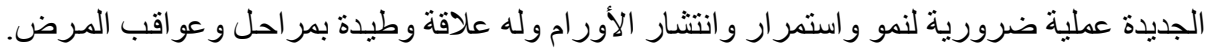

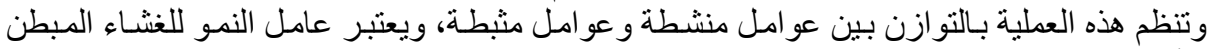

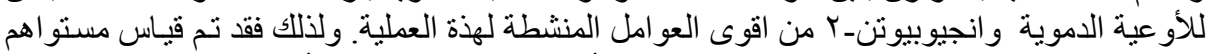

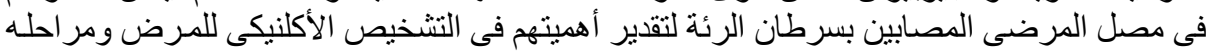
وفيفية علاجهر الترخي وقد اثتملت الدراسة ـ ـ شخصا ـ ـ تم تقسيمه الى ثلاث مجمو عات :

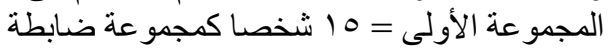

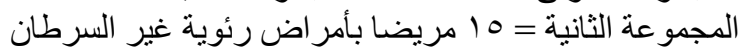

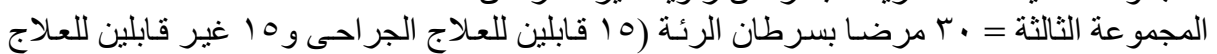

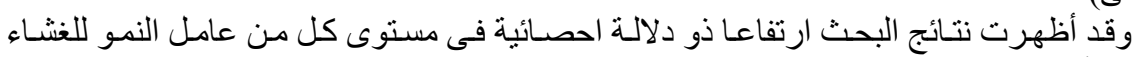

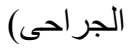

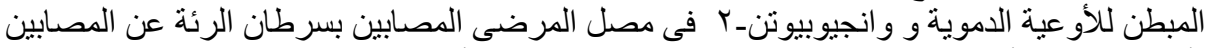

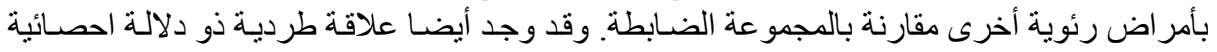

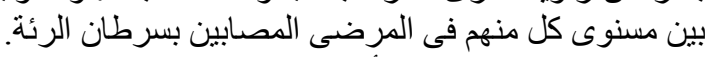

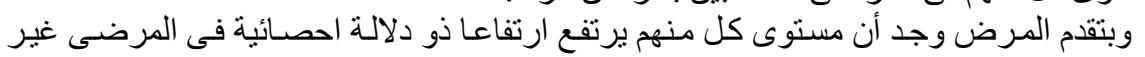

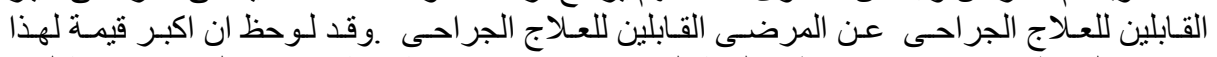

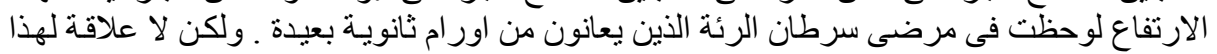

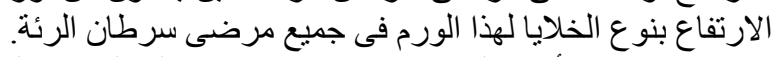

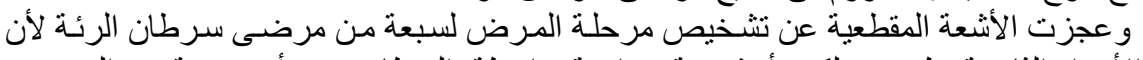

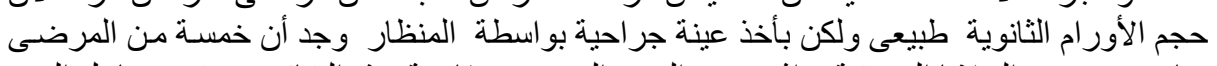

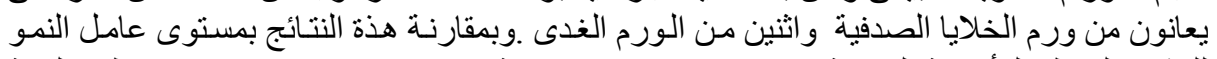

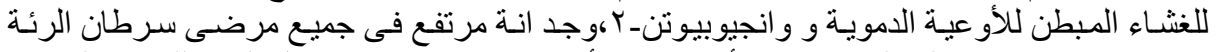

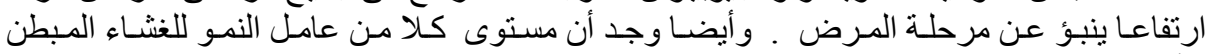

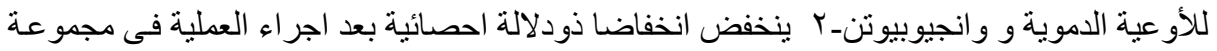

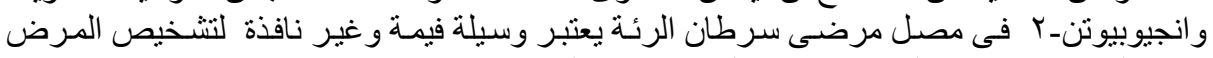
ومر احله واختيار خطة العلاج ومتابعة المرضي بعد العلاج. 